\title{
How Much Evidence is Necessary for Pharmacogenomic Testing Implementation?
}

\section{Y. W. Francis Lam*}

Department of Pharmacology, University of Texas Health Science, Center at San Antonio and College of Pharmacy, University of Texas at Austin, USA

The levels and strength of evidence expected for demonstration of clinical utility (defined as ability to predict clinical outcome and the added value over standard care) of pharmacogenomics-guided drug therapy continue to be a significant barrier for implementation of pharmacogenomic testing in clinical practice. Given the scope of the current healthcare expenditure and evidence-based driven clinical environment, any clinical trial to validate clinical utility is expected to not only be hypothesis-driven but also extensive in terms of time and sample size. As an example, the ongoing multi-site, randomized controlled Pharmacogenomics of Anti-platelet Intervention-2 (clinicaltrials.gov NCT01452152) trial compares pharmacogenomicguided antiplatelet therapy versus standard care on cardiovascular events in 7,200 patients undergoing percutaneous coronary intervention, but the results likely will not be available until 2015. In the meantime, clinicians continue to debate and disagree on the quantity and quality of data that are scientifically appropriate but at the same time realistically achievable, $[1,2]$ and based on the lack of consensus, payers continue to decline reimbursement for pharmacogenomic biomarker tests, [3] even though at times the tests are much less expensive than the drugs that are paid for.

Traditional randomized, placebo-controlled, clinical studies provide evidence on drug efficacy and safety in a large patient cohort in an attempt to compensate for statistical issues related to multiple confounding variables that include, but not limited to, disease and population heterogeneities and drug response variabilities. Although usually considered the gold standard, such trials might not be the best model for validation of pharmacogenomics biomarkers, since the emphasis and clinical value of pharmacogenomics are more geared towards the outliers (the non-responders, the poor metabolizers, or the ultra-rapid metabolizers). The important question to be addressed then is "Are we sacrificing patient care on the insistence of waiting for proofof-value via the evidence-based approach"?

With this dilemma, paradigm shifts in our approaches to the levels of evidence would be necessary. Instead of simply waiting for conclusive evidence from yet-to-be completed randomized, controlled clinical studies, different steps should be taken to facilitate the genotyping implementation in clinical environments, whilst at the same time examine comparative effectiveness and/or cost-effectiveness of pharmacogenomics-guided therapy using a variety of approaches. Recent progresses at major medical institutions and centers in the United States as well as overseas demonstrated the practical approaches to, and clinical values of, implementation [4-7]. The approaches of preemptive (pre-prescription) genotyping in conjunction with pop-up alerts embedded within electronic medical record system adopted at some of the centers represent bold initial steps of applying scientifically valid pharmacogenomics information [4-6]. Other parallel developments include evidence-based clinical recommendation with treatment guidelines available through the Clinical Pharmacogenetics Implementation Consortium, the European Science Foundation, and the British Association of Dermatology [8-10].

It is crystal clear to all stakeholders in the field of pharmacogenomics that pharmaceutical companies have very little financial incentive to conduct randomized controlled clinical trials for out-of-patent marketed drugs, which account for a very significant portion of the pharmacogenomic literature. Therefore, a rethinking of the types of study design and/or the quality of study data to move the field forward has to be adopted. Replication of genotype-drug response associations in multiple cohorts or inclusion of replication data, for example, with warfarin and simvastatin $[11,12]$, represents approaches that can add further evidence of clinical validity (defined as ability to identify patients at risk for adverse drug reactions, or to differentiate responders from non-responders). The recent report of comparative effectiveness between pharmacogenetic-guided warfarin therapy in 504 patients versus standard care in 1,866 patients provides a strong validation to the clinical benefit associated with the use of pharmacogenomic biomarkers in a real world setting, and included encouraging data regarding the clinical utility of a simple dosing algorithm [13]. Prospective enrichment-design clinical trials that are stratified according to disease subtypes, inclusion of patients more likely to respond, or exclusion of patients highly susceptible to adverse drug reactions, have been advocated [14], and might further reduce the required number of participants for the purpose of a clinical trial.

In this regards, the evidence-based review that showed lack of association between CYP450 genotypes and the metabolism, effectiveness, and side effects of Selective Serotonin Reuptake Inhibitors (SSRIs) in the management of depression [15] has been cited much often as the rationale that pharmacogenomic biomarker tests could not improve outcome and should not be used in decision-making. However, given the flat-dose response relationship, a wide therapeutic index, and the metabolism of most SSRIs mediated by multiple CYP isoenzymes, some of which are not polymorphic, the SSRIs would not be good candidate for testing the clinical validity and utility of genotype-based pharmacogenomic therapy. In contrast, the "singlearm" prospective intervention study by Epstein et al. [16] provides how real-world study not only provide practical information for clinicians, but also lay the foundation for additional studies, if necessary, as was shown in the case for warfarin [13].

Finally, conducting practical clinical trials in real world setting, as has been proposed in the past $[17,18]$, that whilst seemingly uncontrolled, can provide results that are more relevant to practitioners and payers alike. Such real-world studies include those reported for warfarin $[13,16]$, and the concept can be adopted even at the grassroot level on a much smaller scale, in clinics or physician offices. As an

*Corresponding author: Y. W. Francis Lam, Department of Pharmacology School of Medicine, University of Texas Health Science Center at San Antonio, 7703 Floyd Curl Drive San Antonio, Texas, USA, Tel: 210-567-8319; Fax: 210-5678328; E-mail: lamf@uthscsa.edu

Received October 01, 2012; Accepted October 03, 2012; Published October 06 , 2012

Citation: Francis Lam YW (2012) How Much Evidence is Necessary for Pharmacogenomic Testing Implementation? Clin Exp Pharmacol 2:e107. doi:10.4172/2161-1459.1000e107

Copyright: @ 2012 Francis Lam YW. This is an open-access article distributed under the terms of the Creative Commons Attribution License, which permits unrestricted use, distribution, and reproduction in any medium, provided the original author and source are credited. 
Citation: Francis Lam YW (2012) How Much Evidence is Necessary for Pharmacogenomic Testing Implementation? Clin Exp Pharmacol 2:e107. doi:10.4172/2161-1459.1000e107

example, elimination of tolbutamide in carriers of $C Y P 2 C 9^{*} 2$ and CYP2C $9^{*} 3$ variants were $50 \%$ and $84 \%$ slower, respectively, than in homozygous carriers of $C Y P 2 C 9^{*} 1$ [19]. However, to-date there is no prospective, randomized, controlled clinical trial to evaluate whether $50 \%$ to $90 \%$ dose reductions would be appropriate in clinical practice for patients who are carriers of the two allelic variants. Monitoring of tolbutamde efficacy can be easily done after implementation of these dosage reductions, and such effort could constitute the first step of gathering information regarding clinical utility of CYP2C9 genotyping in optimizing tolbutamide therapy.

One of the issues embedded within the concept of clinical utility for a particular genetic test is whether there is risk associated with the use of the test and whether that risk outweighs the benefit offered by the test. While the concern is definitely legitimate for a multitude of reasons with respect to disease susceptibility, especially if there is no available intervention or modification to mitigate the risk; the significance of the concern is somewhat less for testing metabolic capacity and/or drug target sensitivity, both of which would be useful information in optimizing drug therapy. This is especially true for drugs with a narrow therapeutic index where knowledge of all patient-specific factors, including genetic influences, that predispose drug-related toxicities are needed for preventing or reducing morbidity and mortality.

\section{References}

1. Levine GN, Bates ER, Blankenship JC, Bailey SR, Bittl JA, et al. (2011) 2011 ACCF/AHA/SCAI Guideline for Percutaneous Coronary Intervention: a report of the American College of Cardiology Foundation/American Heart Association Task Force on Practice Guidelines and the Society for Cardiovascular Angiography and Interventions. Circulation 124: e574-651.

2. Johnson JA, Roden DM, Lesko LJ, Ashley E, Klein TE et al. (2012) Clopidogrel: a case for indication-specific pharmacogenetics. Clin Pharmacol Ther 91: 774776 .

3. Cohen J, Wilson A, Manzolillo K (2012) Clinical and economic challenges facing pharmacogenomics. Pharmacogenomics $\mathrm{J}$.

4. Crews KR, Cross SJ, McCormick JN, Baker DK, Molinelli AR, et al. (2011) Development and implementation of a pharmacist-managed clinical pharmacogenetics service. Am J Health Syst Pharm 68: 143-150.

5. Nelson DR, Conlon M, Baralt C, Johnson JA, Clare-Salzler MJ, et al. (2011) University of Florida Clinical and Translational Science Institute: transformation and translation in personalized medicine. Clin Transl Sci 4 400-402.

6. Pulley JM, Denny JC, Peterson JF, Bernard GR, Vnencak-Jones, et al. (2012). Operational Implementation of Prospective Genotyping for Personalized Medicine: The Design of the Vanderbilt PREDICT Project. Clin Pharmacol Ther 92: 87-95.
7. Chen P, Lin JJ, Lu CS, Ong CT, Hsieh PF, et al. (2011) Carbamazepineinduced toxic effects and HLA-B ${ }^{*} 1502$ screening in Taiwan. N Engl J Med 364 1126-1133.

8. Relling MV, Klein TE (2011) CPIC: Clinical Pharmacogenetics Implementation Consortium of the Pharmacogenomics Research Network. Clin Pharmacol Ther 89:464-7.

9. Becquemont L, Alfirevic A, Amstutz U, Brauch $H$, Jacqz-Aigrain $E$, et al (2011) Practical recommendations for pharmacogenomics-based prescription: 2010 ESF-UB Conference on Pharmacogenetics and Pharmacogenomics. Pharmacogenomics 12: 113-124.

10. Fargher EA, Tricker K, Newman W, Elliott R, Roberts SA, et al. (2007) Current use of pharmacogenetic testing: a national survey of thiopurine methyltransferase testing prior to azathioprine prescription. J Clin Pharm Ther 32: 187-95.

11. Chan SL, Suo C, Lee SC, Goh BC, Chia KS, et al. (2012) Translational aspects of genetic factors in the prediction of drug response variability: a case study of warfarin pharmacogenomics in a multi-ethnic cohort from Asia. Pharmacogenomics J 12: 312-318.

12. Link E, Parish S, Armitage J, Bowman L, Heath S, et al. (2008) SLCO1B variants and statin-induced myopathy-a genomewide study. N Engl J Med 359: 789-799.

13. Anderson JL, Horne BD, Stevens SM, Woller SC, Samuelson KM, et al. (2012) A randomized and clinical effectiveness trial comparing two pharmacogenetic algorithms and standard care for individualizing warfarin dosing (CoumaGenII). Circulation 125: 1997-2005.

14. Stingl Kirchheiner JC, Brockmoller J (2011) Why, when, and how should pharmacogenetics be applied in clinical studies?: current and future approaches to study designs. Clin Pharmacol Ther 89: 198-209.

15. EGAPP Working Group (2007) Recommendations from the EGAPP Working Group: testing for cytochrome P450 polymorphisms in adults with nonpsychotic depression treated with selective serotonin reuptake inhibitors. Genet Med 9 : 819-825.

16. Epstein RS, Moyer TP, Aubert RE, O KDJ, Xia F, et al. (2010) Warfarin genotyping reduces hospitalization rates results from the MM-WES (MedcoMayo Warfarin Effectiveness study). J Am Coll Cardiol 55: 2804-2812.

17. Brass EP (2010) The gap between clinical trials and clinical practice: the use of pragmatic clinical trials to inform regulatory decision making. Clin Pharmacol Ther 87: 351-355.

18. Tunis SR, Stryer DB, Clancy CM (2003) Practical clinical trials: increasing the value of clinical research for decision making in clinical and health policy. JAMA 290: 1624-1632

19. Kirchheiner J, Bauer S, Meineke I, Rohde W, Prang V, et al. (2002) Impact of CYP2C9 and CYP2C19 polymorphisms on tolbutamide kinetics and the insulin and glucose response in healthy volunteers. Pharmacogenetics 12: 101-109. 